\title{
PENGARUH DUKUNGAN SOSIAL TERHADAP MOTIVASI DAN SCHOOL WELL BEING PADA PELAJAR DI INDONESIA
}

\author{
Rini Maspupah ${ }^{1}$, Sherly Salsa Violina², \\ Viyata Vira Diva ${ }^{3}$, Syahnur Rahman ${ }^{4}$ \\ 1,2,3,4 Program Studi Psikologi, Universitasi Pendidikan Indonesia, \\ rinimaspupah@upi.edu
}

\begin{abstract}
Academic problems can cause any negative impact on students. An immature psychological condition sometimes also adds problems for students. If this happens for a long time, it will cause a decrease in learning motivation. This study aims to analyse the effect of social support on motivation and school well being on students in Indonesia. Social support is believed to encourage learning for students, furthermore, school well-being in students will grow because they feel their needs are met. This study uses literature review methods from several journals taken in Google Scholar and Springer. The results found that motivation and social support had a positive and significant influence on school well-being. Therefore, school well-being can be improved through increased motivation and social support.
\end{abstract}

Keywords : Social Support; Motivation; School Well-Being

\begin{abstract}
ABSTRAK
Masalah akademik dapat menimbulkan dampak negatif bagi pelajar. Kondisi psikologis yang tidak matang ada kalanya juga turut menambah beban bagi pelajar. Jika hal ini terjadi dalam waktu yang lama, maka akan menimbulkan penurunan pada motivasi belajar. Penelitian ini bertujuan untuk menganalisis pengaruh dukungan sosial terhadap motivasi dan school well-being pada pelajar di Indonesia. Dukungan sosial diyakini dapat menimbulkan semangat belajar bagi pelajar, lebih lanjut, school well-being pada pelajar akan tumbuh karena merasa kebutuhannya terpenuhi. Penelitian ini menggunakan metode literature review dari beberapa jurnal yang diambil dari Google Scholar dan Springer. Hasil penelitian menemukan bahwa motivasi dan dukungan sosial memiliki pengaruh positif dan signifikan terhadap school well-being. Oleh karena itu, school well-being dapat ditingkatkan melalui peningkatan motivasi dan dukungan sosial.
\end{abstract}

Kata Kunci: Dukungan Sosial; Motivasi; School Well-Being

\section{Pendahuluan}

Pendidikan merupakan hal yang sangat penting untuk dilakukan di zaman sekarang, karena mereka yang berpendidikan akan dianggap dapat berpikir secara matang, teratur, dan baik. Di samping itu, orang yang berpendidikan akan memiliki input yang baik juga, sehingga ia dapat memahami potensi dirinya secara maksimal. Pendidikan juga dianggap sebagai hal yang vital bagi suatu bangsa karena dijadikan sebagai tolak ukur kemajuan rakyatnya. Negara yang maju akan memiliki tingkat dan kesadaran pendidikan yang tinggi, sedangkan negara berkembang akan memiliki tingkat dan kesadaran pendidikan yang rendah.

Meskipun begitu proses belajar tidak selalu berjalan lancar pada faktanya, karena motivasi belajar seseorang dapat berubah setiap saat. Beberapa masalah seperti menurunnya motivasi, kondisi keluarga yang tidak kondusif, dan kondisi pencahayaan rumah yang kurang baik dipandang dapat mengurangi minat seseorang untuk mempelajari dan memahami sesuatu yang baru. Salah satu cara yang dapat dilakukan untuk membantu meningkatkan proses belajar siswa yaitu dengan terjaganya kesejahteraan siswa di sekolah atau yang sering disebut sebagai school well-being. Menurut Konu dan Rimpela (dalam Rabbani, 2019), school well-being didefinisikan sebagai keadaan yang memungkinkan individu memuaskan kebutuhan-kebutuhan 
dasarnya, baik materil maupun non-materil yang terbagi menjadi beberapa aspek yaitu having (kondisi sekolah), loving (hubungan sosial), being (pemenuhan diri), dan health (keadaan).

Husnul Khatimah (dalam Rabbani, 2019) mengungkapkan bahwa terdapat banyak faktor yang mempengaruhi school well-being, di antaranya adalah faktor internal dan eksternal. Faktor eksternal meliputi infrastruktur yang baik, manajemen sekolah, interaksi yang baik antara guru maupun teman serta dukungan penuh dari orang tua. Sedangkan faktor internal adalah modal dasar personal siswa yaitu siswa yang memiliki motivasi belajar yang tinggi, disiplin yang tinggi, kerjasama yang baik, memiliki strategi belajar yang baik, serta inisiatif belajar yang baik. Dari sekian banyak faktor yang mempengaruhi school well-being, penelitian ini memilih untuk fokus meneliti faktor internal yaitu motivasi dan faktor eksternal yaitu dukungan sosial. Berdasarkan penelitian sebelumnya ditemukan adanya pengaruh school wellbeing terhadap motivasi belajar siswa. Sucianti dan Prasetya (dalam Hasanah \& Sutopo, 2020) juga menjelaskan bahwa kondisi lingkungan belajar dan upaya pengajar dalam mengajar peserta didik merupakan salah satu yang mempengaruhi motivasi belajar, lingkungan belajar yang kondusif akan mendorong siswa untuk selalu termotivasi dalam belajar, dan sarana prasarana yang memadai juga merupakan faktor yang mempengaruhi motivasi belajar, siswa akan merasa senang dan lebih mudah mempelajari materi pembelajaran karena sarana prasarana yang mendukung setiap kegiatan pembelajaran.

Selain itu, menurut hasil penelitian terdapat pengaruh yang signifikan antara persepsi dukungan sosial dengan kesejahteraan di sekolah. Hasil ini serupa dengan studi bahwa ada hubungan yang kuat antara persepsi dukungan sosial dan kesejahteraan di sekolah, meliputi dukungan dari orang tua, dukungan dari teman, dan dukungan dari guru sebelumnya (Rahma, dkk., 2020). Hasil penelitian yang dilakukan oleh Marwan (dalam Noviyanti \& Kumalasari, 2020) menunjukkan bahwa dukungan akan membuat semakin tinggi percaya diri siswa dan meningkatkan hasil belajar mereka. Ketika siswa memiliki rasa percaya diri, maka mereka akan meningkatkan kompetensi dan menunjukkan performa dengan baik (King, Ganotice, \& Watknis, 2012).

Untuk menunjang minat seseorang dalam belajar, maka harus ada motivasi yang kuat dalam dirinya. Motivasi belajar merupakan suatu dorongan bagi individu untuk melakukan aktivitas belajar yang berasal dari dalam diri maupun luar diri (Andriani \& Rasto, 2019). Motivasi bukan hanya berbentuk dorongan, melainkan berbagai aksi seperti pengarahan, penggerakan, dan penyaluran yang dilakukan individu untuk mencapai tujuan akhir yang diinginkannya. Ketika seorang individu memiliki motivasi yang tinggi untuk belajar, maka ia akan memiliki prestasi yang baik.

Di samping motivasi diri yang kuat, dukungan sosial dari keluarga dan lingkungan juga dibutuhkan agar semakin memacu individu untuk meraih impiannya. Tarmidi dan Rambe (dalam Emeralda \& Kristiana, 2017) mengungkapkan salah satu manfaat dukungan sosial, utamanya dari keluarga, adalah untuk meningkatkan regulasi diri anak ketika belajar. Ketika regulasi diri anak sudah baik, maka ia akan dapat menentukan tujuan dari belajar yang dilakukannya.

Dari hasil beberapa penelitian yang telah dilakukan, dan kami belum menemukan penelitian yang membahas pengaruh dukungan sosial dan motivasi terhadap school well-being. Dengan demikian, kami tertarik untuk melakukan penelitian terkait pengaruh dukungan sosial dan motivasi terhadap school well-being. 


\section{Kajian Pustaka}

\section{Dukungan Sosial}

Menurut kodratnya manusia adalah sosial, yang mana manusia itu tidak mungkin hidup sendiri dalam memenuhi kebutuhan hidupnya sehingga selalu bersama-sama dengan orang lain, baik itu individu dengan individu, individu dengan kelompok, dan kelompok dengan kelompok. Dalam hidupnya manusia memerlukan suatu Dukungan Sosial. Dukungan sosial merupakan suatu bentuk dukungan atau tingkah laku yang menumbuhkan perasaan nyaman dan membuat individu percaya bahwa ia dihormati, dihargai, dan dicintai orang lain bersedia memberikan perhatian dan keamanan. Selain itu dapat Dukungan sosial diartikan sebagai sesuatu yang diterima individu berupa pemberian bantuan, pertolongan dan semangat dari keluarga yang diwujudkan dalam bentuk informasi, tingkah laku dan materi ketika individu menghadapi kesulitan atau masalah yang membuatnya tidak nyaman (Maslihah, S, 2011).

Dukungan sosial mengacu pada ketersediaan sumber daya yang dapat diberikan lingkungan kepada seorang individu untuk membantu mereka mengatasi masalah. Selain itu dukungan sosial juga bisa mencangkup pemberian informasi verbal maupun nonverbal, bantuan tingkah laku atau pemberian materi yang membuat individu merasa disayang, diperhatikan dan bernilai. Dalam penerapannya ada tiga konsep dukungan sosial yaitu keterikatan sosial, persepsi dukungan sosial, dan dukungan sosial aktual. Selain itu Secara spesifik terdapat enam fungsi sosial yang berbeda atau "provisions (ketersediaan)" yang dapat diperoleh dari hubungan dengan orang lain. Keenam fungsi sosial tersebut diperlukan individu untuk merasa didukung secara memadai dan untuk menghindari kesepian. Enam fungsi sosial tersebut adalah tersedianya sarana dan informasi (guidance), jaminan bahwa orang lain dapat diandalkan untuk memberikan bantuan nyata (reliable alliance), pengakuan atau penghargaan terhadap kemampuan dan kualitas individu (reassurance of worth), pengekspresian kasih sayang dan cinta yang diterima individu (attachment), kesamaan minat dan perhatian serta rasa memiliki dalam suatu kelompok (social integration), dan perasaan individu bahwa ia dibutuhkan oleh orang lain (opportunity to provide nurturance) (Nugraha, M. F, 2020).

Dukungan sosial dapat diperoleh dari mana saja, salah satunya dari keluarga. Keluarga juga sebagai tempat sosialisasi sosial pertama individu. Segala kebutuhan individu, fisik dan psikis, untuk kali pertama terpenuhi dari lingkungan keluarga. Individu menempatkan keluarga sebagai tempat untuk bercerita, tempat mengeluarkan keluhan bila ia menghadapi persoalan dan tumpuan harapan. Dukungan sosial menjadi penting karena manusia secara umum memiliki kebutuhan sosial untuk memberi umpan balik atau ikatan emosional yang memberikan kepuasan dan bisa juga menjadi saling tukar informasi yang akan membuat manusia itu tidak hanya tumbuh fisiknya namun juga dapat berkembang kognitifnya. Sehingga dalam hal ini dilihat dari segala jenis karakter dan juga lapisan masyarakat semua orang membutuhkan Dukungan sosial untuk meningkatkan derajat hidupnya (Thohiroh, H., Novianti, L. E., \& Yudiana, W, 2019).

\section{Motivasi}

Salah satu faktor yang mempengaruhi proses belajar adalah motivasi. Motivasi berasal dari kata "motif" yang memiliki pengertian maksud dasar seseorang dalam melakukan suatu pekerjaan. Selain itu, motivasi juga dapat diartikan sebagai daya penggerak seseorang dalam melakukan sesuatu untuk mencapai hal yang diinginkannya (Damanik, 2019). Oleh karena itu, motivasi dianggap sebagai salah satu hal penting untuk meningkatkan semangat belajar siswa. Dengan motivasi yang tinggi, siswa akan menjadi tertantang untuk belajar dan mencari tahu hal-hal baru. Motivasi terbagi menjadi empat jenis, yaitu motivasi intrinsik yang berasal dari dalam diri individu dan tidak memerlukan stimulus dari luar, motivasi ekstrinsik yang berasal dari luar diri individu termasuk di dalamnya dukungan sosial, motivasi primer yang didasarkan dari motif dasar individu, yaitu aspek biologis dan jasmani, dan motivasi sekunder yang dipelajari oleh individu (Sulfemi, 2018) 
Seperti yang telah disinggung di atas, adanya motivasi akan membangkitkan minat siswa untuk berprestasi sehingga hasil belajar yang dihasilkan memuaskan, walaupun begitu motivasi siswa seringkali mengalami penurunan. Salah satu penyebabnya adalah karena fasilitas belajar yang kurang memadai. Semakin lengkap fasilitas belajar yang tersedia, maka akan semakin meningkat pula motivasi siswa. Di masa pandemi seperti ini, fasilitas belajar yang memadai seperti ventilasi yang cukup serta sinyal dan kecepatan internet yang baik sangatlah diperlukan.

Selain faktor fasilitas penunjang belajar, menurut sebuah penelitian adanya dukungan sosial dari orang terdekat, khususnya orang tua, dapat membantu meningkatkan motivasi siswa (Arzieva dkk., 2020). Siswa akan merasa senang ketika orang tuanya membantu mer eka dalam mengerjakan tugas atau memberi semangat ketika hendak mempelajari hal baru. Selain itu, ilmu pengetahuan yang tinggi yang dimiliki orang tua akan turut membantu siswa untuk semangat belajar.

\section{School Well Being}

School well-being merupakan sebuah konsep yang merujuk pada model konseptual kesejahteraan yang dikemukakan oleh Allardt. Allardt (dalam Hasanah \& Sutopo, 2020) mendefinisikan kesejahteraan sebagai keadaan yang memungkinkan individu untuk memuaskan kebutuhan-kebutuhan dasarnya, yang mencakup kebutuhan material maupun nonmaterial. Berdasarkan konsep kesejahteraan yang dikemukakan oleh Allardt tersebut, Konu dan Rimpela (dalam Hasanah \& Sutopo, 2020) mengembangkan kesejahteraan dalam konteks sekolah melalui kajian terhadap beberapa literatur, seperti sosiologis, pendidikan, psikologis, dan peningkatan kesehatan, hingga menghasilkan konsep school well-being yang dikenal sekarang ini. Kemudian Konu dan Rimpela (dalam Rabbani, 2019) mendefinisikan school wellbeing sebagai suatu kondisi atau keadaan saat seseorang dapat memuaskan kebutuhan dasarnya di lingkungan pendidikan yang berkaitan langsung dengan kegiatan belajar mengajar, selain itu kriteria keadaan sekolah yang sejahtera adalah sekolah yang memungkinkan siswa untuk memenuhi kebutuhan dasar akademisnya. Kebutuhan dasar yang dimaksud terdiri dari fasilitas sekolah yang meliputi lingkungan fisik maupun pelayanan yang diberikan untuk siswa, lingkungan sosial yang meliputi hubungan siswa dan guru serta teman sekelas baik dalam hal akademik maupun non-akademik, kesempatan untuk meningkatkan pengetahuan dan keterampilan siswa, dan kesehatan siswa menjadi tolak ukur kesejahteraan sekolah. School well-being pada siswa merupakan merupakan kehidupan emosional yang positif yang dihasilkan dari keselarasan antara faktor lingkungan, kebutuhan pribadi, dan harapan siswa di sekolah (dalam Nanda \& Widodo, 2015). Tujuan utamanya adalah tidak hanya sekedar pemenuhan kesejahteraan siswa saja, melainkan juga pemenuhan akan prestasi, potensi, serta kemampuan fisik maupun mental siswa (Nanda \& Widodo, 2015). School well-being penting untuk diterapkan karena dengan school well-being siswa mampu belajar secara efektif sehingga akan memberi kontribusi positif pada sekolah dan lingkungan sekitar (Rabbani, 2019).

Konu dan Rimpela (dalam Noviyanti \& Kumalasari, 2020) membagi school well-being berdasarkan empat dimensi. Yang pertama adalah having. Merupakan kondisi atau keadaan dari tempat belajar meliputi lingkungan di dalam dan disekitar sekolah (Rahma dkk., 2020). Definisi having merujuk pada persepsi siswa mengenai sejauh mana aspek fisik dan non-fisik lingkungan sekolah mendukung kegiatan belajar siswa (Noviyanti \& Kumalasari, 2020). Kondisi tempat belajar meliputi lingkungan di dalam dan disekitar sekolah. Kondisi di sekitar sekolah diharapkan merupakan tempat yang nyaman untuk belajar, bebas dari kebisingan, ventilasi yang baik, termasuk juga kurikulum, ukuran kelompok, jadwal pelajaran dan hukuman serta peraturan sekolah. Aspek berikutnya meliputi pelayanan siswa, seperti ada atau tidaknya kantin yang dirasakan nyaman oleh siswa, perpustakaan yang dapat menunjang proses belajar, pelayanan kesehatan dan konseling di sekolah (Kartasasmita, 2017). Kedua adalah loving. Merupakan hubungan siswa dengan lingkungannya, termasuk lingkungan sosialnya, 
hubungannya dengan siswa lainnya, dinamika kelompok serta hubungan antara lingkungan rumah dengan sekolahnya (Rahma dkk., 2020). Dimensi loving merujuk pada persepsi siswa mengenai sejauh mana kebutuhan mereka akan relasi yang sehat dengan teman, guru maupun staf di sekolah terpenuhi (Noviyanti \& Kumalasari, 2020).

Ketiga adalah being. Merujuk pada persepsi siswa mengenai sejauh mana kebutuhan siswa akan pengembangan potensi diri serta dukungan terpenuhi di sekolah (Noviyanti \& Kumalasari, 2020). Hasil penelitian Urdan dan Schoenfelder (dalam Noviyanti \& Kumalasari, 2020) menunjukkan bahwa ketika siswa didorong dan diizinkan untuk ikut serta dalam proses pembelajaran di lingkungan dimana mereka merasa diperhatikan, didukung, dan terhubung secara sosial dengan guru dan teman sebaya, dan bila mereka diberikan tugas yang bermakna dan tepat, maka mereka akan semakin termotivasi. Keempat adalah health. Merujuk pada persepsi siswa mengenai kondisi kesehatan mereka, termasuk symptom psikosomatis, penyakit kronis, dan penyakit ringan (Konu \& Rimpela, 2002 dalam Noviyanti \& Kumalasari, 2020).

Husnul Khatimah (dalam Rabbani, 2019) mengungkapkan bahwa terdapat faktor internal dan eksternal yang mempengaruhi school well-being. Faktor eksternal meliputi infrastruktur yang baik, manajemen sekolah, interaksi yang baik antara guru maupun teman serta dukungan penuh dari orangtua. Sedangkan faktor internal adalah modal dasar personal siswa yaitu siswa yang memiliki motivasi belajar yang tinggi, disiplin yang tinggi, kerjasama yang baik, memiliki strategi belajar yang baik serta inisiatif belajar yang baik.

\section{Metode Penelitian}

Dalam penelitian ini, desain penelitian yang digunakan adalah dengan literature review. Creswell John W. (dalam Habsy, 2017) mendefinisikan studi literatur sebagai cara meringkas dan mengumpulkan data dari media tertulis seperti buku, jurnal, artikel, atau dokumen lain yang berisikan teori-teori dari masa lalu maupun masa kini. Jenis penulisan yang digunakan adalah studi literatur review yang berfokus pada hasil penelitian yang berkaitan dengan topik atau variabel penulisan. Dalam hal ini, peneliti mencoba untuk mengumpulkan data menggunakan kata kunci school well being, motivasi, dan dukungan sosial dari jurnal atau artikel yang didapat melalui Springer dan Google Scholar.

\section{Hasil dan Pembahasan}

Berdasarkan penelusuran data menggunakan kata kunci dukungan sosial, motivasi, dan school well-being diketahui bahwa dukungan sosial dan motivasi yang dimiliki pelajar akan mempengaruhi school well-being mereka. Konu dan Rimpela (dalam Noviyanti \& Kumalasari, 2020) membagi school well-being berdasarkan empat dimensi, yaitu having, loving, being, dan health. Dukungan sosial yang diterima siswa termasuk ke dalam dimensi loving yang merujuk pada sejauh mana kebutuhan mereka akan relasi yang sehat dengan teman, guru maupun staf di sekolah terpenuhi. Sementara itu, menurut Husnul Khatimah (dalam Rabbani, 2019) motivasi merupakan salah satu faktor internal yang dapat mempengaruhi school well-being pelajar.

Penelitian yang dilakukan oleh Noona Kiuru, Ming-Te Wang, Katariina Salmela-Aro, Lasse Kannas, Timo Ahonen, dan Riikka Hirvonen dalam judul Associations between Adolescents' Interpersonal Relationships, School Well-being, and Academic Achievement during Educational Transitions menyatakan bahwa kedekatan pelajar dengan orang tua dan teman sekolah akan meningkatkan school well-being (Kiuru dkk., 2020). Selain itu, tingkat kepuasan sekolah yang tinggi akan mendorong hubungan yang baik dengan orang tua, teman sekolah, dan guru, sementara hubungan ini akan terganggu oleh tingkat stres sekolah yang tinggi. 
Dukungan sosial didefinisikan oleh Jupe dan Foote (Handono, 2013) sebagai sumber daya sosial yang dapat membantu individu dalam menghadapi kejadian yang menekan. Dukungan sosial juga diartikan sebagai suatu pola interaksi yang positif atau perilaku menolong yang diberikan pada individu yang membutuhkan dukungan. Peranan yang positif dari persepsi dukungan sosial teman terhadap kesejahteraan subjektif di sekolah menunjukkan bahwa jika siswa mempersepsikan bahwa temannya menyediakan dukungan sosial saat mereka membutuhkan, maka evaluasi siswa terhadap kehidupannya di sekolah akan menjadi lebih positif atau kesejahteraan siswa di sekolah meningkat. Temuan ini juga melengkapi penelitian sebelumnya, dimana dukungan sosial dari teman sekelas memiliki implikasi penting bagi kesejahteraan subjektif siswa di sekolah (Jiang dkk., 2013; Liu dkk., 2015; Tian dkk., 2013). Interaksi sosial yang baik antar teman merupakan salah satu hal yang paling berkontribusi pada well-being remaja di sekolah (Alcantara dkk., 2017; Awang dkk., 2014; Wijayanti, 2018). Selain teman sebaya gurulah yang berperan dalam peningkatan kesejahteraan subjektif di sekolah pada aspek school satisfaction. Dengan kata lain, semakin positif persepsi dukungan sosial guru maka akan semakin positif pula kepuasannya di sekolah. Temuan penelitian ini serupa dengan penelitian sebelumnya yang menyatakan bahwa pada remaja awal, dukungan sosial dari guru secara signifikan memprediksi school satisfaction (Tennant dkk., 2015; Tian dkk., 2013).

Dalam hal motivasi, pelajar yang memiliki tingkat motivasi rendah diyakini akan kesulitan dalam mencapai prestasi belajarnya, maka dari itu diperlukan kecerdasan biologis dan keyakinan dari dalam diri pelajar bahwa dirinya mampu mencapai tujuan itu. Selanjutnya, faktor eksternal berupa dukungan sosial ada kalanya juga dibutuhkan untuk membangkitkan motivasi pelajar. Dukungan ini dapat berupa pemfasilitasan sarana dan prasarana yang memadai, kemampuan mengajar guru yang baik, motivasi dari guru yang tinggi, dan lingkungan sosial yang mendukung. Di samping itu, motivasi sekunder atau motivasi yang dipelajari oleh individu juga diperlukan untuk menunjang minat belajar, mengingat Teori Pembelajaran Sosial juga merupakan hal yang penting. Orang tua atau pengajar dapat memberikan contoh sederhana seperti rajin membaca dan berlatih soal kepada pelajar supaya pelajar tertarik untuk mengikutinya. Selain itu, untuk meningkatkan motivasi belajar siswa maka aspek-aspek seperti durasi pembelajaran, frekuensi pembelajaran, dan tingkat pengorbanan harus diperhatikan (Andriani \& Rasto, 2019).

\section{Kesimpulan dan Saran Kesimpulan}

Berdasarkan hasil studi literatur di atas mengenai pengaruh dukungan sosial dan motivasi terhadap school well-being pelajar di Indonesia, maka dapat ditarik kesimpulan bahwa tiingkat school well-being pelajar di Indonesia dapat mengalami peningkatan maupun penurunan bergantung pada dukungan sosial dan motivasi yang dimiliki pelajar tersebut. Pelajar yang menerima dukungan sosial yang baik dari orang tua, teman, dan guru akan mempunyai school well-being yang lebih tinggi dibandingkan pelajar yang kurang mendapatkan dukungan sosial. Selain itu, pelajar yang menerima dukungan dari lingkungan sosialnya juga akan lebih termotivasi untuk belajar sehingga ia akan memiliki prestasi yang baik. Tidak hanya dukungan sosial dan motivasi, masalah-masalah kecil seperti ventilasi dan pencahayaan juga dapat mempengaruhi minat seseorang untuk belajar. Hal tersebut bisa menjadi pembelajaran bagi para orang tua dan guru supaya mampu menciptakan lingkungan belajar yang lebih baik agar pelajar mampu menunjukkan performa terbaik mereka.

\section{Saran}

Berdasarkan hasil studi literatur yang telah dilakukan, maka saran yang dapat diberikan kepada peneliti selanjutnya adalah untuk mengembangkan faktor-faktor lain yang berpengaruh dalam peningkatan atau penurunan school well-being seperti emotional literacy, tingkat disiplin 
pelajar, strategi belajar, maupun prokrastinasi. Dalam hal metode, peneliti berikutnya dapat melanjutkan dengan metode yang berbeda seperti studi lapangan.

\section{Daftar Pustaka}

Andriani, R., \& Rasto, R. (2019). Motivasi belajar sebagai determinan hasil belajar siswa. Jurnal Pendidikan Manajemen Perkantoran, 4(1), 80. https://doi.org/10.17509/jpm.v4i1.14958

Arzieva, D. T., Matveeva, I. A., Ғofurova, Y. K., Mamatova, N. A., \& Igamova, D. N. (2020). Factors affecting students' motivation in learning english. International Journal of Scientific and Technology Research, 9(3), 3323-3325.

Damanik, B. E. (2019). Pengaruh Fasilitas Dan Lingkungan Belajar Terhadap Motivasi Belajar. Publikasi Pendidikan, 9(1), 46. https://doi.org/10.26858/publikan.v9i1.7739

Emeralda, G. N., \& Kristiana, I. F. (2017). Hubungan Antara Dukungan Sosial Orang Tua Sekolah $\begin{array}{llll}\text { Menengah Pertama. } & \text { Empati, }\end{array}$ https://www.neliti.com/id/publications/178064/hubungan-antara-dukungan-sosialorang-tua-dengan-motivasi-belajar-pada-siswa-sek

Habsyi, B. A. (2017). Seni Memahami Penelitian Kualitatif Dalam Bimbingan Dan Konseling: Studi Literatur. JURKAM: Jurnal Konseling Andi Matappa, 1(2), 90. https://doi.org/10.31100/jurkam.v1i2.56

Hasanah, M., \& Sutopo, S. (2020). Pengaruh School Well-Being Terhadap Motivasi Belajar Siswa di Madrasah Aliyah. Ummul Qura: Jurnal Institut Pesantren Sunan Drajat (INSUD) Lamongan, 15(2), 34-42.

Kartasasmita, S. (2017). Hubungan antara school well-being dengan rumination. Jurnal Muara Ilmu Sosial, Humaniora, Dan Seni, 1(1), 248-252.

Kiuru, N., Wang, M. Te, Salmela-Aro, K., Kannas, L., Ahonen, T., \& Hirvonen, R. (2020). Associations between Adolescents' Interpersonal Relationships, School Well-being, and Academic Achievement during Educational Transitions. Journal of Youth and Adolescence, 49(5), 1057-1072. https://doi.org/10.1007/s10964-019-01184-y

Maslihah, S. (2011). Prestasi Akademik Siswa Smpit Assyfa Boarding School. Psikologi Undip, 10(2), 103-114.

Nanda, A., \& Widodo, P. B. (2015). Efikasi diri ditinjau dari school well-being pada siswa sekolah menengah kejuruan di Semarang. Jurnal Empati, 4(4), 90-95.

Noviyanti, A., \& Kumalasari, D. (2020). Peran school well being terhadap motivasi sekolah siswa Sekolah Menengah. Jurnal Psikogenesis, 8(1), 78-88.

Nugraha, M. F. (2020). Dukungan Sosial dan Subjective Well Being Siswa Sekolah Singosari Delitua. Jurnal Penelitian Pendidikan, Psikologi Dan Kesehatan (J-P3K), 1(1), 1-7. https://doi.org/10.51849/j-p3k.v1i1.5

Rabbani, M. D. R. (2019). HUBUNGAN ANTARA STRESS AKADEMIK DAN SCHOOL WELL-BEING PADA SISWA SMA DI YOGYAKARTA. Universitas Islam Indonesia. 
Rahma, U., Pramitadewi, K. P., Faizah, F., \& Perwiradara, Y. (2020). Pengaruh persepsi dukungan sosial terhadap kesejahteraan di sekolah siswa SMA. Jurnal Psikologi Ulayat: Indonesian Journal of Indigenous Psychology, 7(2), 163-176.

Sulfemi, W. B. (2018). Hubungan Motivasi Belajar Dengan Hasil Belajar Ips Di Smp Kabupaten Bogor. Edutecno, 18(106), 1-12. https://doi.org/10.31227/osf.io/eqczf

Thohiroh, H., Novianti, L. E., \& Yudiana, W. (2019). Peranan Persepsi Dukungan Sosial terhadap Kesejahteraan Subjektif di Sekolah pada Siswa Pondok Pesantren Modern. Psympathic: Jurnal Ilmiah Psikologi, 6(2), 131-144. https://doi.org/10.15575/psy.v6i2.5323 